\title{
Modeling and Analysis of Mobile Service Processes by Example of the Housing Industry
}

\author{
Volker Gruhn ${ }^{1}$, André Köhler ${ }^{1}$, Robert Klawes ${ }^{2}$ \\ ${ }^{1}$ University of Leipzig, Chair of Applied Telematics / e-Business, Klostergasse 3, 04109 \\ Leipzig, Germany \\ \{gruhn, koehler\}@ebus.informatik.uni-leipzig.de \\ ${ }^{2}$ Deutsche Bank AG, Alfred-Herrhausen-Allee 16-24, 65760 Eschborn, Germany \\ \{robert.klawes@db.com\}
}

\begin{abstract}
This article describes the method of Mobile Process Landscaping by example of a project in which the service processes of a company from the housing industry were analyzed regarding their mobile potential. This analysis was conducted with the aim to organize these processes more efficiently in order to realize cost savings. Therefore, the method of Mobile Process Landscaping, which is introduced in this article, was used. The method refers to the stage of requirements engineering in the software process. It is shown how the initial situation of the company was analyzed, which alternative process models on the basis of mobility supporting technology were developed and how these alternatives were economically evaluated. Furthermore, it is shown how first restrictions for the software and system design were made on the basis of one process model. Finally, it is shown how the Mobile Process Landscaping method can be used to verify whether the adoption of mobility supporting technology is suitable to obtain a defined goal and which requirements such a solution needs to fulfill.
\end{abstract}

Keywords. business process modeling and analysis, mobile business processes

\section{Introduction}

Since the availability of broadband radio networks and the receded costs for appropriate devices the use of mobility-supporting technology has become an interesting opportunity for companies to optimize selected business processes and to increase their efficiency. Mobile business processes are characterized by a high degree of mobility of the involved persons and by a lack of knowledge about the next location of the person. Often a connection to IT-systems of the company would be desirable. In such processes, media-breaks, long processing times, inefficient routes and lacks of information can be observed. The use of mobility supporting technology offers the opportunity to solve these problems. But therefore a systematic analysis of the professional requirements on the basis of business processes is necessary.

This article deals with the method of Mobile Process Landscaping (MPL) by whose use the described tasks can be handled. Referring to the software process the 
activities and their results can be assigned to the requirements engineering. The use of this method is shown by example of the technical service processes taken from a company of the housing industry.

In chapter 2 the MPL method is explained. First, mobile business processes are defined (2.1.). Afterwards, the structure of the method (2.2.) as well as its aim (2.3.) are described. Subsequently, an overview about related work is given (2.4). Chapter 3 shows the usage of the MPL method by example of a company of residential trade and industry. That chapter corresponds to the structure of the MPL method as explained in section 2.3. Chapter 4 draws a conclusion.

\section{Mobile Process Landscaping Method}

\subsection{Mobile Business Processes}

The term „business process“ was defined by numerous authors ([1], [2], [3], [4], [5], [6]). Below, we follow the commonly used definition of Davenport [2] according to which a business process can be understood as ,,a specific ordering of work activities across time and place, with a beginning, an end, and clearly identified inputs and outputs: a structure for action."

A business process can be decomposed in different levels into sub-processes. If a sub-process is not decomposable it is called "activity." Thus, a business process can be understood as an abstract description of workflows in a company. The actual occurrence of such a business process in reality is called a business process instance.

In the following, only business processes with a specific distribution structure and thus a certain mobility of the process-executing person are considered. We suppose that mobility is given when for at least one activity an "uncertainty of location" exists. This assumption is based on the concept of "location uncertainty" by Valiente and van der Heijden [7], according to which the place of the execution of an activity can be different in different instances of the business process or the place can change during the execution of an activity. Thus, we deal with a mobile activity within a business process. Because multiple mobile activities are conceivable, and a mobile activity often affects the whole business process, the complete business process is called "mobile business process".

Furthermore, it can be noticed that the "uncertainty of location" is externally determined. This assumption implies that the location uncertainty is caused by external factors and that the process-executing person has therefore no freedom of choice regarding the place of the process execution. Beyond, often a cooperation with external resources (from the process-point of view) is needed during the execution of the process. This fact restricts the term "mobile business process" to the necessity of cooperation with external resources within the considered activity, for instance caused by the need for communication or coordination with other persons or interaction with other objects. 
Considering this, we propose the following definition: A mobile business process is a business process, in which

a. at least one person is involved, which executes its tasks in different locations,

b. the actual location of the task-execution is known just vague and/or just short before the beginning of the task,

c. this uncertainty (b) is determined externally and can not be fully controlled by the process-executing person.

On the basis of this definition, two conclusions can be drawed. First, the definition implies that the assigned task causes the mobility of the involved person. The mobile worker need to appear physically on the specified location because there exists a resource (damaged device, customer) necessary for the solution of his task. Second, it is not relevant for this definition whether mobile information technology is used or not. In fact, mobile information technology will be the key for the realization of an efficient work flow in the majority of the cases.

\subsection{Structure of the Method}

Subsequently, the structure of the method is explained. Figure 1 shows the essential steps of the method. First, the company needs to define the objective which is to be achieved by use of this method. Usually, the goal is to optimize the process parameter (personnel) costs, the duration of the process or the quality of the produced goods and services.

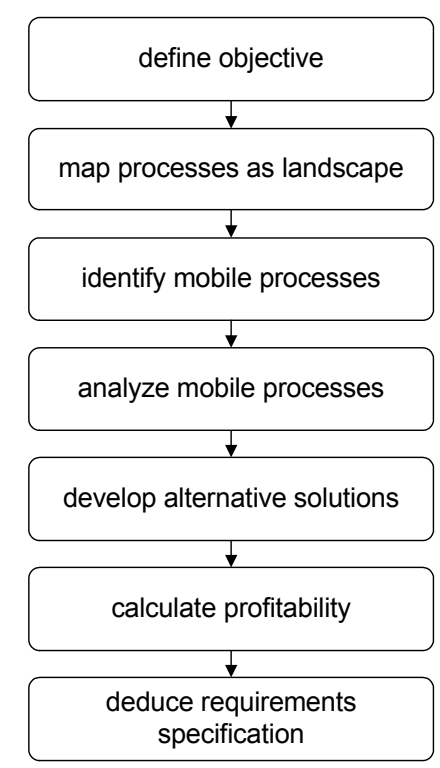

Fig. 1. Steps of the MPL-Method

As soon as the objective is defined one can start with acquiring the processes and depicting them as process landscape. The process landscape shows relations between 
the main business processes and allows its user to recognize dependencies between processes very early. During the next step, those sub-processes characterized by a high degree of mobility of the process-executing person need to be identified. Therefore, the method provides an assessment scheme which is explained in chapter 3.3. If mobile processes are identified, an analysis is necessary.

During this step, shortcomings in the process flow resulting from the mobility of the process-executing person can be discovered. On the basis of these insights new process versions can be developed in order to avoid the recognized shortcomings. This can be conducted by constraining or supporting the mobility within the process. Subsequently, the different alternatives need to be evaluated by an economically point of view. If a positive decision for the realization of one alternative has been reached, first requirements specifications and restrictions for the software architecture can be deduced. Further information about the Mobile Process Landscaping method can be found in ([8], [9], [10], [11]).

\subsection{Aim of the MPL Method}

By the use of the MPL method within the business process model of a company the following can be achieved:

- the discovery of mobile processes in the business process model,

- the analysis of potential for optimization by the support or elimination of the mobile processes,

- the development of alternative solutions based on the use of mobility-supporting technology,

- the economic evaluation of those alternatives and

- the deduction of general conditions and requirements for the software and system design for the selected alternative.

On the basis of these results alternative solutions can be evaluated according to the companies strategic goals. The architecture of the resulting system can be developed on the foundation of clear professional guidelines.

\subsection{Related Work}

A number of recent publications show that efficiency and effectiveness of certain activities can be improved through the use of mobile technologies ([7], [12], [13]). The mentioned examples are case studies describing successfully released solutions in different companies. However, how these companies choose the described business processes and activities for the use of mobile technologies remain open questions.

Frequently, a technology-driven approach can be observed for realising potential benefits, which adjusts processes corresponding to the available features of certain mobile devices. But often, a large number of complex processes with many involved people prevails, e.g. in large companies and corporate groups. Such an approach may then lead to wrong decisions, especially in the long term. In our opinion, the process 
of decision-making about use and design of a mobile information system needs to be systematic and comprehensible.

Beyond, the question for the quality of mobility is an important one in this context. As stated in [14] user mobility is often distinguished into personal and terminal mobility. Particularly, the movement of the terminal and therewith the terminal mobility has come to the fore in the recent years. In contrast, the personal mobility has received less attention. In our opinion, it is necessary to focus research on this topic because of the constraints for software development resulting from certain requirements of the specific kind of mobility.

Kakihara and Sorensen [19] discuss the notion of mobility in distinguishing spatial, temporal and contextual mobility. This is an important contribution to the definition of mobility in this article.

Dustdar and Gall [16] as well as Sairamesch et al. [17], [18] describe frameworks for distributed and mobile collaboration which can be used to develop software architectures for mobile systems. These frameworks are of particular interest for the MPL method because it is the methods aim to provide a systematic deduction of constraints for the software architecture on the basis of the process model.

Gupta and Moitra [20] introduce an highly interesting technology integration approach for pervasive IT Infrastructure. The aim of this approach is partly the same as of the MPL method (focusing on the protection of investments and maximizing the returns) but has a more generic character.

\section{The Use of MPL in an Industry Case}

In the following, the application of the MPL method is shown by example of a municipal company called LWB, located in Leipzig, Germany. Its main task is to assure a socially acceptable apartment supply for a great number of citizens. For this purpose, LWB builds and maintains apartments particular in the low price segment. These apartments are mainly located in multi-storey houses which are affected by vacancy more than averagely.

The economic situation in the concerned real estate market is characterized by a considerable oversupply of apartments. Because of the large share of vacant apartments (approx. 17\%) as well as the continuous migration of prosperous inhabitants into the suburbs, landlords compete for the lowest rents on the market. In this situation the company LWB is confronted with high losses of revenue and high costs for maintenance. In order to overcome this situation the company induced a variety of steps, basically to lower the costs. In this context, an examination and analysis of the internal workflow was planned in order to discover potential for optimization.

The company started quite fast to focus on its maintenance processes because of the very large number of apartments (approx. 12,000) and therefore the very large number of process recurrences. Beyond, these processes are characterized by a high degree of mobility of the process-executing person. These facts promised a high potential for optimization. Therefore, the company LWB asked the University of Leipzig to conduct an analysis by the use of the MPL method. The precise proceeding 
during this project and the achieved results are introduced in the following. The explanations are aligned on the structure of the method as described in Figure 1.

\subsection{Defining Objective}

The company aimed at preferably high cost-savings by an optimization of the business processes with a high degree of mobility of the process-executing person. The use of mobile technology therefore was favored. The analysis should be conducted for the business process "Technical Service." As a result, a couple of alternative technical and process solutions as well as an economical evaluation and first requirement specifications of them was expected.

\subsection{Mapping Processes as Landscape}

\subsubsection{Depiction of Processes}

The business process "Technical Service" consists of the sub-processes "Maintenance," "Administration," "Allocation of Costs," "Billing" and "Recording of Consumption Values." These business processes are depicted as a process landscape (PL) to recognize their essential relations to each other (Figure 2). The sub-processes are evaluated by the level of value added and the assumed degree of mobility.

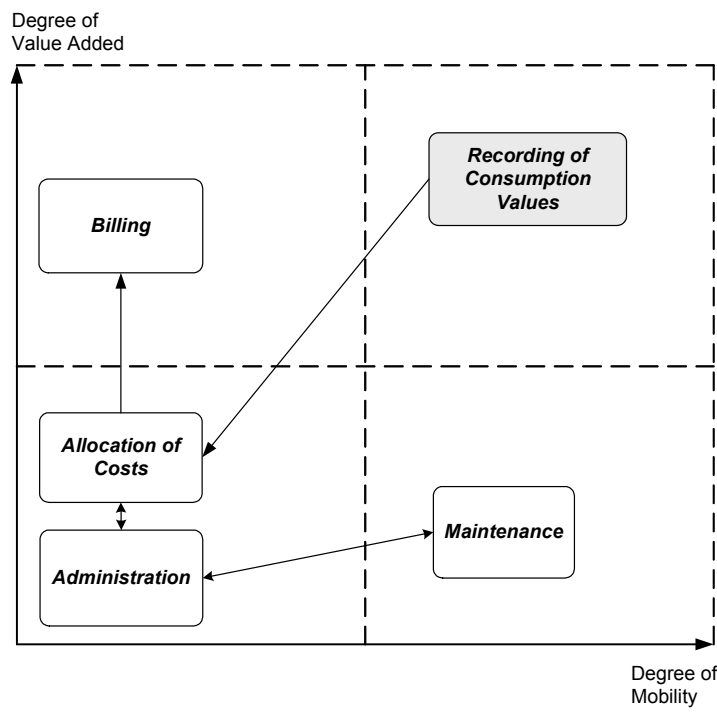

Fig. 2. Figure 1. PL "Technical Service"

The sub-processes "Allocation of Costs" and "Administration" were classified as slightly value adding and not mobile. The sub-process "Billing" was classified as value adding but not mobile. The sub-process "Maintenance" is extremely mobile but 
just slightly value adding due to the fact that necessary repairs need to be achieved but no revenue can be associated to them. The sub-process "Recording of Consumption Values" is extremely mobile and value adding. Because of this classification the sub-process "Recording of Consumption Values" was examined. Figure 3 shows the detailed sub-process. The notation in this figure as well as in the following ones is used according to the Business Process Modeling Notation [15]. The sub-process „Recording of Consumption Values“ contains the recording, the transportation and the processing of the consumption values for water and heating. They are measured by appropriate meters for each apartment.

The recording of the consumption values is executed by a subsidiary company of the LWB called WSL. The process starts when the LWB assigns the WSL to record the consumptions in all properties of the company. This assignment is done once a year. The execution of the whole process takes three months for approximately 12.000 apartments in 240 properties. A property is a real estate which contains 50 apartments on average. The LWB sends lists with addresses and tenant data to the WSL to prepare the recording of the consumption values. Subsequently, the WSL processes the acquired lists electronically for the upcoming tasks (process data records). On basis of this information dates for the recording are arranged and efficient tours for the inspection of the apartments are planned (plan tour). Furthermore, for each daily tour paper lists with addresses and tenant data are created. These preparing tasks take about one week.

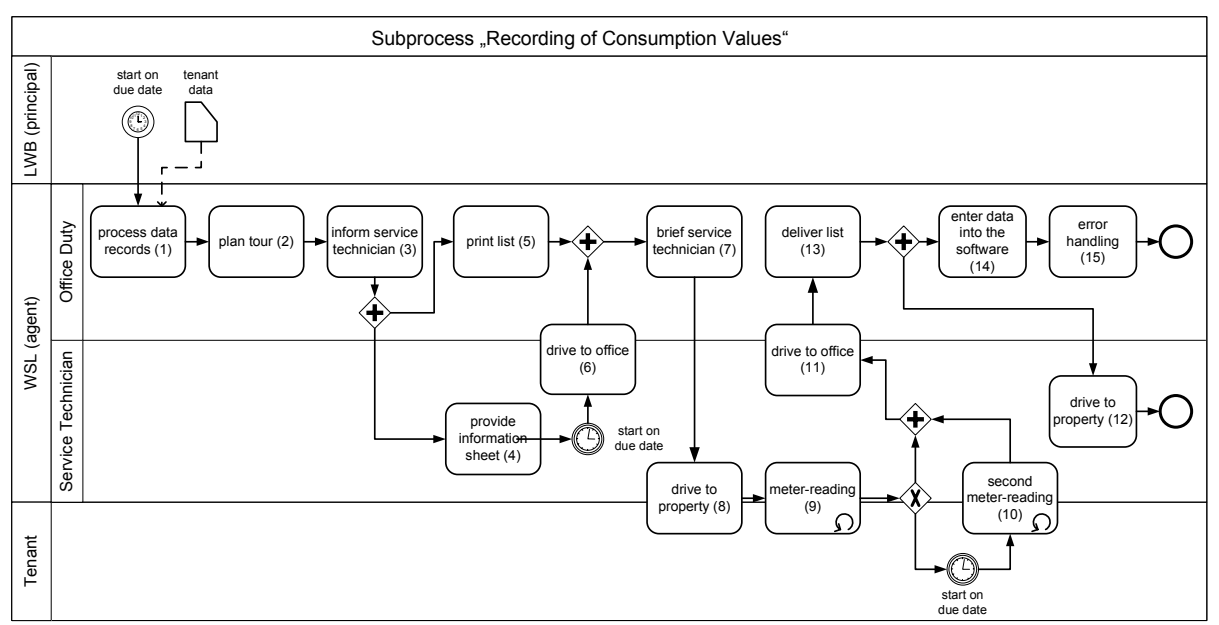

Fig. 3. Recording of consumption values

After completing the tour planning the service technicians get informed about their individual tours (inform service technician). Afterwards, they drive to their assigned properties and attach an information sheet with the recording date to each entrance (provide information sheet). Shortly before the date of recording the service technicians drive to the office duty to get recording lists as well as information about the recording procedure (brief service technician). Then they drive to the properties according to their tour plans and start the recording (meter-reading). 
For each apartment an average of four values need to be recorded. The service technician walks from apartment to apartment and records by hand each value as well as the tenant name and the identification number of each device on his list. This activity takes approximately ten minutes per customer. After the recording the service technician has to drive back to office duty and deliver the recording lists. There the staff transcript the data into the appropriate software.

\subsubsection{Shortcomings of the Process}

Within the process different shortcomings could be found. In approximately ten percent of the cases the tenant is absent, which leads to a repetition of the process starting with a new appointment. If the tenant is absent again the process is repeated a third time at the tenant's own expense. Beyond, there is the danger of transcription errors due to media breaks. They can be caused by inaccurate recordings or by accidentally mixing up the numbers. The company WSL estimates that approximately five percent of the recording lists are wrong without anybody noticing it. Additionally, the staff estimates that around ten percent of the lists are unreadable. In such cases a request by telephone and an adjustment are necessary. Apart from its vulnerability for errors the double-recording causes high efforts. Because of the large number of apartments and the necessary personnel effort the recording of the consumption values is conducted just once a year. In that way, defective or manipulated meters can be recognized just once a year.

Table 1. Costs of "Technical Service"

\begin{tabular}{|l|r|r|r|r|r|}
\hline Activity & $\begin{array}{l}\text { duration } \\
\text { (minutes) }\end{array}$ & $\begin{array}{l}\text { number of } \\
\text { executions } \\
\text { per property }\end{array}$ & $\begin{array}{l}\text { duration per } \\
\text { property } \\
\text { (minutes) }\end{array}$ & $\begin{array}{l}\text { cost per } \\
\text { property } \\
\text { (EUR) }\end{array}$ & $\begin{array}{l}\text { total cost } \\
\text { (EUR) }\end{array}$ \\
\hline process data records & 900 & 0,00 & 3,75 & 1,12 & 268,44 \\
\hline plan tour & 1500 & 0,00 & 6,25 & 1,86 & 447,41 \\
\hline inform service technician & 10 & 0,00 & 0,04 & 0,07 & 17,98 \\
\hline provide information sheet & 5 & 5,00 & 25,00 & 7,46 & 1789,63 \\
\hline print list & 30 & 0,00 & 0,13 & 2,12 & 508,95 \\
\hline drive to office & 30 & 0,33 & 10,00 & 2,98 & 715,85 \\
\hline brief service technicians & 5 & 0,33 & 1,67 & 0,50 & 119,31 \\
\hline drive to property & 30 & 0,33 & 10,00 & 2,98 & 715,85 \\
\hline meter-reading & 10 & 50,00 & 500,00 & 149,14 & 35792,64 \\
\hline second recording & 12 & 5,00 & 60,00 & 17,90 & 4295,12 \\
\hline drive to office & 30 & 0,33 & 10,00 & 2,98 & 715,85 \\
\hline drive to property & 30 & 0,33 & 10,00 & 2,98 & 715,85 \\
\hline deliver list & 5 & 0,00 & 0,02 & 0,07 & 16,49 \\
\hline enter data into software & 2 & 50,00 & 100,00 & 29,83 & 7158,53 \\
\hline error handling & 6 & 5,00 & 30,00 & 8,95 & 2147,56 \\
\hline & & & 766,85 & 230,94 & 55425,47 \\
\hline
\end{tabular}




\subsubsection{Costs of the Process}

Table 1 shows the distribution of the process costs over the single activities. The figured costs of the activities refer to the execution of the activity for one property.

For this calculation only personnel costs are considered. Therefore, an hourly rate of 17.90 EUR was assumed. The whole personnel costs for the process "Recording of Consumption Values“" account for approximately 55,500 EUR.

\subsection{Identification of Mobile Processes}

Not every business process is suitable for an optimization by the use of mobile technology. Because of that potentially mobile sub-processes need to be identified by means of different criteria. Therefore, the MPL method provides an assessment scheme in order to evaluate each activity by different criteria. For the evaluation a scale from 0 (not true) to 2 (true) is used. The small scale limits the subjective discretion of the conducting person.

Table 2. Evaluation of the activities

\begin{tabular}{|c|c|c|c|c|c|c|c|c|c|c|c|}
\hline & \multicolumn{4}{|c|}{ General Potential } & & \multicolumn{3}{|c|}{ Mobile Potential } & \multirow[b]{2}{*}{ 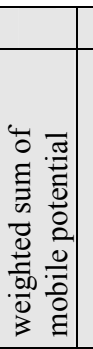 } & \multirow[b]{2}{*}{ છ } \\
\hline & & 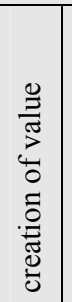 & 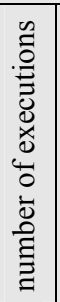 & 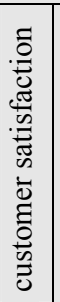 & 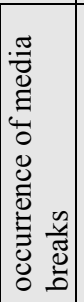 & 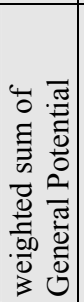 & 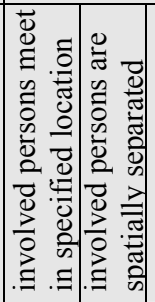 & 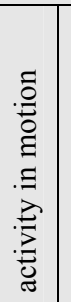 & 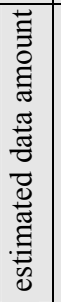 & & \\
\hline \multicolumn{2}{|c|}{ weight } & 1,0 & 1,5 & 0,3 & \begin{tabular}{|l|}
1,8 \\
\end{tabular} & & \begin{tabular}{l|l|}
1,5 & 1,0 \\
\end{tabular} & 0,3 & 0,8 & & \\
\hline No. & Act & & & & & & & & & & \\
\hline 1 & process da & 1,0 & 0,0 & 0,0 & 1,0 & 2,8 & \begin{tabular}{|l|l|}
0,0 & 0,0 \\
\end{tabular} & 0,0 & 2,0 & 1,6 & 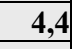 \\
\hline 2 & plan tour & 1,0 & 0,0 & 0,0 & 1,0 & 2,8 & \begin{tabular}{|l|l|}
0,0 & 0,0 \\
\end{tabular} & 0,0 & 2,0 & 1,6 & 4,4 \\
\hline 3 & inform service technician & 0,0 & 0,0 & 0,0 & 0,0 & $\mathbf{0 , 0}$ & \begin{tabular}{|l|l|}
2,0 & 0,0 \\
\end{tabular} & 0,0 & 0,0 & 3,0 & 3,0 \\
\hline 4 & provide information sheet & 0,0 & 0,0 & 1,0 & 1,0 & 2,1 & \begin{tabular}{|l|l|}
0,0 & 0,0 \\
\end{tabular} & 0,0 & 1,0 & 0,8 & 2,9 \\
\hline 5 & print list & 1,0 & 0,0 & 0,0 & 1,0 & 2,8 & \begin{tabular}{|l|l|}
0,0 & 0,0 \\
\end{tabular} & 0,0 & 1,0 & 0,8 & 3,6 \\
\hline 6 & drive to office & 0,0 & 1,0 & 0,0 & 0,0 & 1,5 & \begin{tabular}{|l|l|}
0,0 & 0,0 \\
\end{tabular} & 2,0 & 0,0 & 0,6 & 2,1 \\
\hline 7 & brief service techn & 0,0 & 0,0 & 0,0 & 0,0 & 0,0 & \begin{tabular}{|l|l|}
2,0 & 0,0 \\
\end{tabular} & 0,0 & 0,0 & 3,0 & 3,0 \\
\hline 8 & drive to property & 0,0 & 1,0 & 0,0 & 0,0 & 1,5 & \begin{tabular}{|l|l|}
0,0 & 0,0 \\
\end{tabular} & 2,0 & 0,0 & 0,6 & 2,1 \\
\hline 9 & meter reading & 2,0 & 2,0 & 2,0 & 2,0 & 9,2 & \begin{tabular}{|l|l|}
2,0 & 0,0 \\
\end{tabular} & 0,0 & 2,0 & 4,6 & 13,8 \\
\hline 10 & second recording & 2,0 & 2,0 & 2,0 & 2,0 & 9,2 & \begin{tabular}{|l|l|}
2,0 & 0,0 \\
\end{tabular} & 0,0 & 2,0 & 4,6 & 13,8 \\
\hline 11 & drive to office & 0,0 & 1,0 & 0,0 & 0,0 & 1,5 & \begin{tabular}{|l|l|}
0,0 & 0,0 \\
\end{tabular} & 2,0 & 0,0 & 0,6 & 2,1 \\
\hline 12 & drive to property & 0,0 & 1,0 & 0,0 & 0,0 & 1,5 & \begin{tabular}{l|l|}
0,0 & 0,0 \\
\end{tabular} & 2,0 & 0,0 & 0,6 & 2,1 \\
\hline 13 & deliver list & 1,0 & 0,0 & 0,0 & 0,0 & 1,0 & \begin{tabular}{|l|l|}
2,0 & 0,0 \\
\end{tabular} & 0,0 & 0,0 & 3,0 & 4,0 \\
\hline 14 & enter data into software & 2,0 & 2,0 & 0,0 & 2,0 & 8,6 & \begin{tabular}{|l|l|}
0,0 & 0,0 \\
\end{tabular} & 0,0 & 2,0 & 1,6 & 10,2 \\
\hline 15 & error handling & 2,0 & 2,0 & 2,0 & 2,0 & 9,2 & \begin{tabular}{|l|l|}
0,0 & 2,0 \\
\end{tabular} & 0,0 & 2,0 & 3,6 & 12,8 \\
\hline
\end{tabular}

The criteria can be divided into two different groups. The first group contains universal criteria (General Potential) showing general potential for optimization. They are: 
- creation of value,

- number of executions,

- importance for customer satisfaction and

- occurrence of media breaks.

The second group of criteria (Mobile Potential) allows to assess whether an activity is particularly influenced by the mobility of the process-executing person. They are:

- involved persons meet in specified location,

- involved persons are spatially separated,

- activity in motion and

- estimated amount of data.

Table 2 shows the result of the evaluation with these criteria for the process "Recording of Consumption Values." The single criteria were weighted by the company LWB. Figure 4 shows the result of this analysis.

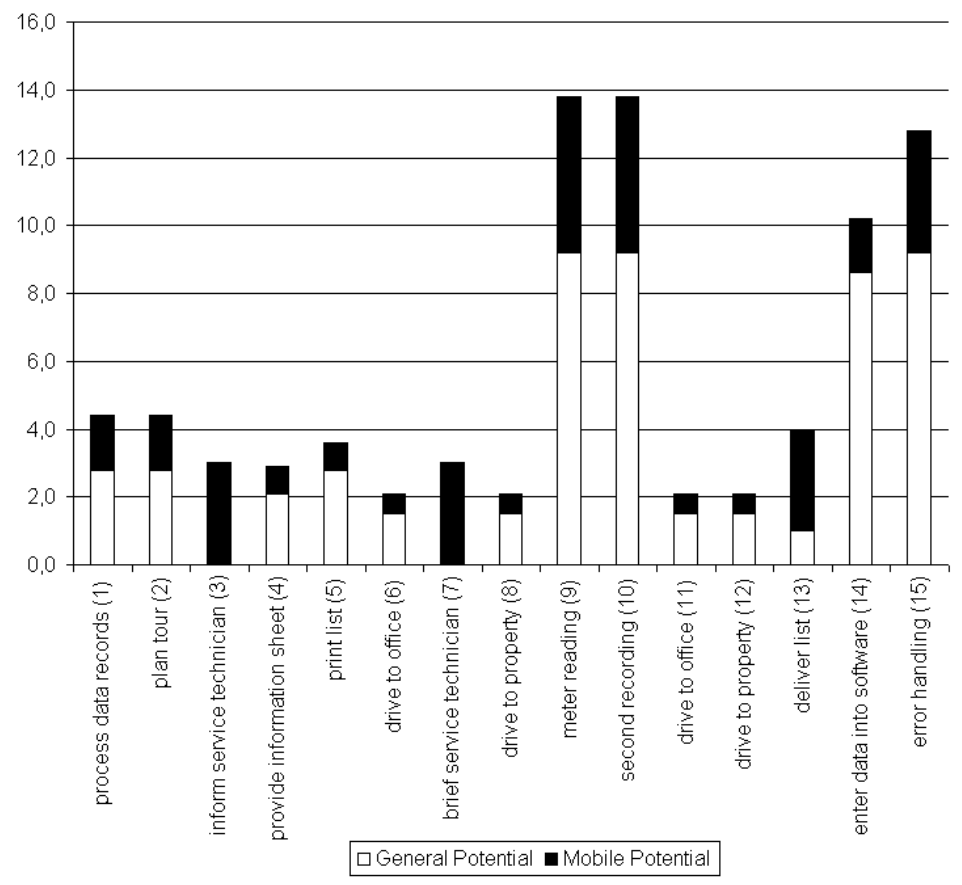

Fig. 4. Potential for optimization per activity

The activities "meter-reading," "second meter-reading," "enter data into software" and "error handling" are characterized by a particularly high potential for optimization. Interestingly, the general potential for optimization for these four activities is evenly distributed whereas the mobile potential for optimization causes differences in the evaluation. Furthermore, the activities "inform service technician," "brief service technician" und "deliver list" are (nearly) exclusively characterized by potential for optimization on the basis of the mobile criteria. On the basis of this analysis the development of a solution aiming at the activities with the biggest potential for optimi- 
zation $(9,10,14$ and 15$)$ was started. To do so, it is very important to interpret the term "Mobile Potential" in the right way. Activities with a high degree of mobile potential are characterized by the effects of physical mobility. This fact does not imply a need for implementing an activity support by means of mobility-supporting technology. It is rather a question of regarding the activities in the process-context and justifying IT-solutions on the whole process. Consequently, this can lead to a completely new structure of the activities. In particular, the IT-solution should have positive effects on the four processes named. The following section shows three alternative solutions which were developed on the basis of this analysis.

\subsection{Developing Alternative Solutions and Calculation of Profitabilaty}

The starting point for the development of a mobile solution are activities which involve the meter-reading $(9,10)$. Therefore, an electronical recording seems to be an opportunity in order to avoid media breaks. It can be done either automatically or manually with the help of the process-executing person. The two propositions "Online Device Support" and "Mobile Device Support" are directed towards the support of the mobility of the service technicians. In contrast, the proposition "Remote Meter-Reading“" focuses on the removal of the mobile activities.

\subsubsection{Online Device Support}

One approach for the solution of the outlined problems is the use of a mobile electronic device. It displays the form electronically and the service technician can enter the consumption values. By the use of a mobile radio network adapter the connection to a central server can be realized. The application can be designed browser-based due to its low complexity. In case that the radio network is not available the consumption values can be noted on paper and transcripted later.

Figure 5 shows the change in the sub-process which results from the implementation of the change. The grey activities are the ones which are dropped compared to the original solution. With this solution the sub-process would be much shorter and simpler in its structure than before. By this solution especially the media breaks between meter-reading and transcription into the software can be avoided.

Furthermore, activities dealing with creation, transport and analysis of the recording lists are avoided. This affects activity 5, 6, 7, 11, 12, 13, 14 and 15. As with this solution the service technician is always online the use of the mobile device for other purposes is possible. For example the support of the sub-process "Maintenance" is imaginable. In the current situation the service technician receives calls on his mobile phone from the office duty and gets informed about trouble messages from tenants. The distribution and the management of these tasks by the use of mobile devices is an interesting opportunity which could be hooked on the solution "Online Device Support".

The estimated costs for the new process according to the scheme showed in Table 1 amount to 45,000 EUR a year. Thereby, only personnel and mobile radio costs were taken into account. That way savings of approximately 10,000 EUR a year can be re- 
alized. In order to realize this solution an investment of around 40,000 EUR is needed.

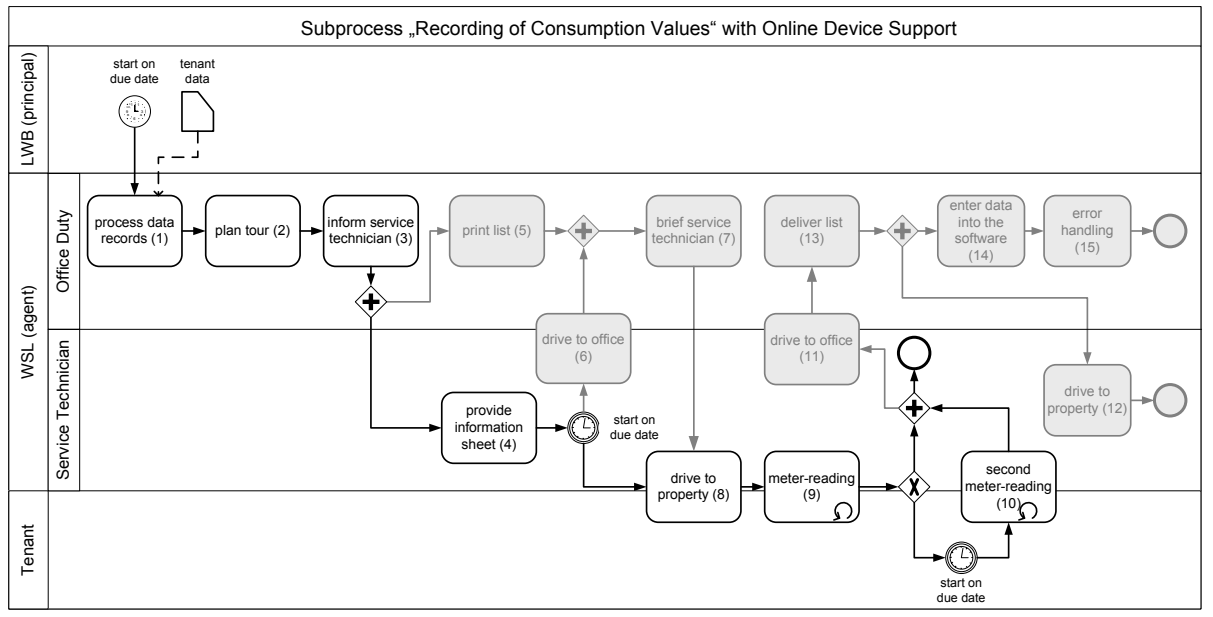

Fig. 5. "Online Device Support"

Thus, the project would be worthwhile about four years after its introduction. The essential advantages of this solution are:

- improvement of those activities with the highest potential for optimization,

- avoidance of media breaks between service technician and office duty,

- reduction of drives, the avoidance of handling of recording lists and

- creation of an important framework for the development of further applications which can support the service technician via the mobile device.

Disadvantages of this solution are:

- in some cases the application might not be available if the radio network is out of reach,

- potentially new sources for errors due to mistakes in handling the device or the software and

- potentially higher risk of process disruption due to failure of the devices or the software.

\subsubsection{Mobile Device Support}

In contrast, an alternative to the solution outlined above could be to retain from the use of a radio network. Then, software needs to be installed at the mobile device in order to support the meter-reading. The recorded consumption values are entered into the software by the service technician and synchronized with the central server.

In this case, the flow of the business process "Recording of Consumption Values" occurs as shown in Figure 5. Inside of the activity "meter-reading" the synchronization with the central server has to be conducted additionally. The synchronization has to be done using a docking station in a determined location (service technician's home, a company's branch). 
Because in this solution no radio network costs occur, the costs per year for the whole process amount to approximately 40.000 EUR (personnel costs). This results in costs savings of about 15.000 EUR a year. To realize this solution an investment of approximately 40.000 EUR is needed. The project would turn worthwhile after three years. The financial savings are assessed as minor ones, but they are even higher than in the solution described above.

The advantages of this solution are the same as in the solution "Online Device Support". An additional advantage is the independence of radio networks, especially in basements and garages. Beyond, there are no costs for the use of radio networks. The disadvantages of this solution are the same as in the one described above.

\subsubsection{Remote Meter-Reading}

A further alternative is the use of an automatic meter-reading system. For this, a device is needed which can be attached to the meter and which has the capability to record the meter-value and to send it via a radio network. For each apartment a central module needs to be installed which sends the acquired data to a central server.

Within this alternative the business process "Recording of Consumption Value" becomes redundant because no human intervention is necessary except in the case of a malfunction. Beyond, the consumption values can be recorded as often as desired.

The estimation of costs of the process was not possible in this project. There is a wide variety of vendors offering suitable devices for the creation of an infrastructure for remote meter-reading. The replacement of all meters would need an investment of millions of EUR. Thus, the realization of this solution only makes sense in combination with the renovation or the new building of houses. Furthermore, prices for the needed devices are anticipated to be on the decrease for the next two years. Hence, an investment at this juncture seems not to be recommendable.

Thus, from the economical point of view this alternative is not realizable measured on the primary goal of cost-savings. Nevertheless, the advantages of such a solution should be named. These are:

- the complete avoidance of the business process "Recording of Consumption Values,"

- a considerable saving of personnel costs,

- the complete avoidance of former sources of errors and media breaks,

- the meter-reading in any desired period (detailed billing and forecasts are possible) and

- an early recognition of malfunctions at the meter (energy losses caused by malfunctions and thievery can be avoided).

Disadvantages of the solution are:

- very high investment needed and

- an additional effort for the maintenance of the devices is needed.

\subsection{Deducing Requirements Specifications}

On the basis of these results the company decided to realize the solution "Online Device Support." The determining factors were the costs-savings per year as well as the 
opportunities for further applications on the basis of the infrastructure of mobile devices and radio networks. On the basis of the professional requirements a requirements specification could be deduced. Thereby, it consciously remains an open question whether a software development is needed or if single components or complete products from specialized vendors can be used.

The draft of the system architecture is shown in Figure 6. The service technician is equipped with a mobile device. Therewith, he can access the mobile application provided by a service provider. The company WSL is connected via WAN with the service provider. The office duty can access all data via the intranet and its ERP-client.

The mobile application needs to provide the following functionality:

- creation of recording lists and tour plans (office duty),

- inquiry of the current state of recording (office duty),

- display of recording lists and tour plans (service technician) and

- recording of the consumption values for each apartment.

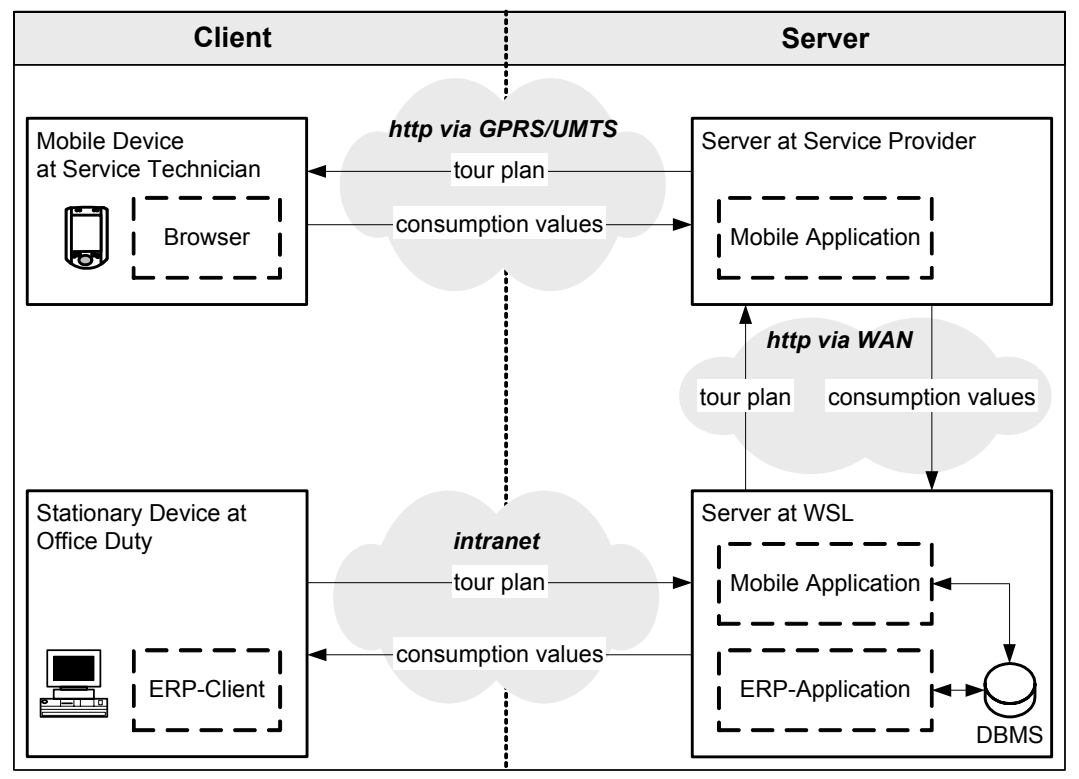

Fig. 6. System architecture

The mobile device needs to fulfil the special requirements of the service technicians. Therefore, the following requirements are defined:

- weight at maximum 500 gram,

- size at maximum (w/h/d) 90/200/50 mm,

- precipitation protection at minimum $100 \mathrm{~cm}$,

- display size at minimum 320/240 pt (coloured),

- slightly water resistant,

- battery runtime at minimum 8 hours,

- docking station with car recharge adapter and 
- large keypad with separate number field.

\section{Summary}

The development of an IT-solution for mobile business processes requires a detailed analysis of the professional requirements as well as an adaptation of the solution onto these requirements. With the described example it was shown that by the help of the MPL method the outlined tasks can be accomplished. The main feature of the method is the analysis of the business processes as well as their dependencies. Furthermore, it was shown how mobile solutions can be evaluated economically in order to justify the needed investment. If the decision for the realization of one alternative solution is made, comprehensive defaults for the system development can be defined on the basis of the detailed professional analysis.

Based on the shown MPL method, further research is planned. First, existing languages for the modeling and analysis of mobile business processes seem not to be suitable for the explicit modeling of mobility. In order to use the process model for the prediction of efficiency and performance of the solution the simulation of the transferred data volume as well as the necessary response time is needed. Second, the systematic deduction of general conditions for the system architecture of a mobile system from the process model would be desirable. Therefore, patterns for mobile business processes as well as corresponding classes of mobile system architectures could be helpful.

\section{Acknowledgements}

The Chair of Applied Telematics / e-Business is endowed by Deutsche Telekom AG.

\section{References}

1. Hammer, M., Champy, J.: Reengineering the corporation: a manifesto for business revolution. Brealey, London (1993)

2. Davenport, T. H.: Process innovation: reengineering work through information technology. Harvard Business School Press, Boston Mass. (1993)

3. Scheer A.: Business process engineering: reference models for industrial enterprises. Springer, Tokyo (1998)

4. Aalst, W. v. d., Hee, K. v.: Workflow Management: Models, Methods, and Systems. MIT Press, Cambridge, (2002)

5. Deiters, W.: Information Gathering and Process Modeling in Petri Net Based Approach. In: van der Aalst, W.M. et al. (eds.): Business Process Management - Models, Techniques, and Empirical Studies, Lecture Notes in Computer Science 1806, Springer, Berlin Heidelberg New York (2000), pp. 274-288 
6. Noor, N. M. M., Papamichail, K. N., Warboys, B.: Process Modeling for Online Communications in Tendering Processes. In: Proceedings of the 29th EUROMICRO Conference 'New Waves in System Architecture', IEEE Computer Society (2003), pp. 17-24

7. Heijden, H. van der, Valiente, P.: Mobile Business Processes: Cases from Sweden and the Netherlands. SSE/EFI Working Paper Series in Business Administration, Stockholm School of Economics (2002)

8. Gruhn, V., Wellen, U.: Process Landscaping: Modeling Distributed Processes and Proving Properties of Distributed Process Models. In: Ehrig, H., Juhás, G., Padberg, J., Rozenberg, G. (Eds.): Unifying Petri Nets - Advances in Petri Nets, Lecture Notes in Computer Science 2128, Springer, Berlin Heidelberg New York (2001), pp. 103-125

9. Köhler, A., Gruhn, V.: Effects of Mobile Business Processes on the Software Process. In: Proceedings of 5th International Workshop on Software Process Simulation and Modeling, $26^{\text {th }}$ International Conference on software engineering, IEE, Stevenage UK (2004), pp. 228231

10. Köhler, A., Gruhn, V.: Analysis of Mobile Business Processes for the Design of Information Systems. In Bauknecht, K., Bichler, M., Pröll, B. (eds.): Proceedings of $5^{\text {th }}$ International Conference on Electronic Commerce and Web Technologies, Lecture Notes in Computer Science 3182, Springer, Berlin Heidelberg New York (2004), pp. 238-247

11. Gruhn, V., Wellen, U.: Structuring Complex Software Processes by 'Process Landscaping'. In Conradi, R. (ed.): Proceedings of $7^{\text {th }}$ EWSPT European Workshop on Software Process Technology, Lecture Notes in Computer Science 1780, Springer, London (2000), pp. 138149

12. Jorstad, I., Thanh, D. v., Dustdar, S.: An Analysis of Service Continuity in Mobile Services. In Proceedings of the 13th IEEE International Workshops on Enabling Technologies: Infrastructure for Collaborative Enterprises, IEEE Computer Society, Washington, DC, USA (2004), pp. 121-126

13. Nielsen, C., Sondergaard, A.: Designing for mobility - an integration approach supporting multiple technologies. In: Proceedings of NordiCHI, Royal Institute of Technology, Stockholm, Sweden (2000), pp. 23-25

14. Thai, B., Wan, R., Seneviratne, A., Rakotoarivelo, T.: Integrated personal mobility architecture: a complete personal mobility solution. In Chlamtac, I. et al. (eds.): Journal of Mobile Networks and Applications, vol. 8, Kluwer Academic Publishers, Hingham (2003), pp. 27-36

15. White, S. A.: Business Process Modeling Notation, BPMI.org, 2003.

16. Dustdar, S., Gall, H.: Architectural concerns in distributed and mobile collaborative systems. In Hellwanger, H. et al. (eds.): Journal of Systems Architecture, Elsevier Science, Amsterdam (2003), pp. 457-473

17. Sairamesh, J., Goh, S., Stanoi, I., Padmanabhan, S., Li, C. S.: Disconnected processes, mechanisms and architecture for mobile e-business. In Chlamtac, I. et al. (eds.): Journal of Mobile Networks and Applications, vol. 9, Kluwer Academic Publishers, Hingham (2004), pp. 651-662

18. Sairamesh, J., Goh, S., Stanoi, I., Li, C. S., Padmanabhan, S.: Commerce and Business : Self-managing, disconnected processes an mechanisms for mobile e-business. In: Proceedings of the $2^{\text {nd }}$ International Workshop in Mobile Commerce, International Conference on Mobile Computing and Networking, ACM Press, New York NY USA (2002), pp. 82-89

19. Kakihara, M., Sorensen, C.: Expanding the mobility concept. ACM SIGGROUP Bulletin, vol. 22, no. 3, ACM Press (2001), pp. 33-37

20. Gupta, P., Moitra, D.: Evolving a pervasive IT infrastructure: a technology integration approach. In: Journal of Personal and Ubiquitous Computing, vol. 8, no. 1, Springer, London (2004), pp. 31-41 